\title{
Comparative impact of two continuing education activities targeted at COPD educators on educational outcomes: protocol for a non-randomized controlled study using mixed methods
}

Myriam Gagné ${ }^{1,2}$, Jocelyne Moisan ${ }^{3,4}$, Sophie Lauzier ${ }^{3,4}$, Christine Hamel ${ }^{5}$, Patricia Côté ${ }^{6}$, Jean Bourbeau ${ }^{6,7,8}$ and Louis-Philippe Boulet ${ }^{1,2,6,9^{*}}$

\begin{abstract}
Background: Therapeutic patient education (TPE) improves quality of life and reduces health care utilization among patients with chronic obstructive pulmonary disease (COPD). However, benefits from TPE might depend on the performance of the educators and training is needed to ensure the effective delivery of TPE interventions. Based on the framework by Moore et al. (J Contin Educ Health Prof 29:1-15, 2009), we will compare the impact of two continuing education (CE) activities on TPE in regard to the following educational outcomes: (1) learning, (2) self-report of competence, (3) performance of the educators, and (4) outcomes of COPD patients who will meet the newly trained educators for TPE.
\end{abstract}

Methods: We will conduct a non-randomized controlled study using mixed methods. Educators will first participate in a CE activity on TPE that will include a role-playing simulation (experimental group) or in a lecture on TPE (comparison group) and then will perform TPE in COPD patients. Among educators, we will assess: (1) learning, by measuring knowledge about TPE, and (2) self-report of competence using self-administered questionnaires before and after the activity. Then, after the CE activity, we will assess (3) educators' performance levels in delivering TPE by rating a videotaped TPE intervention. In COPD patients who will meet the newly trained educators for TPE after either CE activity, we will assess (4) quality of life and resource utilization using interviewer-administered questionnaires, before and after TPE. Statistical analyses will compare the experimental group against the comparison group using multivariate models. Using a semi-structured interview guide, we will conduct interviews with educators and perform content analysis. Results will be integrated in order that qualitative results further explain the quantitative ones.

Discussion: To the best of our knowledge, this is the first controlled mixed methods study to compare the impact of two CE activities on TPE in regard to four educational outcomes. We believe this study will serve as a model for evaluating CE activities on TPE. Results from this study could increase educators' performance levels in delivering effective TPE interventions, and, in turn, COPD patient outcomes.

Trial registration: The study was registered on https://linicaltrials.gov/ (NCT02870998) on March 15, 2016.

Keywords: Education, continuing, Pulmonary disease, chronic obstructive, Patient education as topic, Revised Bloom's taxonomy

\footnotetext{
* Correspondence: Ipboulet@med.ulaval.ca

${ }^{1}$ Knowledge Translation, Education and Prevention Chair in Respiratory and

Cardiovascular Health, Laval University, Quebec City, QC, Canada

${ }^{2}$ Quebec Heart and Lung Institute, Laval University, Quebec City, QC, Canada

Full list of author information is available at the end of the article
}

(c) The Author(s). 2018 Open Access This article is distributed under the terms of the Creative Commons Attribution 4.0 International License (http://creativecommons.org/licenses/by/4.0/), which permits unrestricted use, distribution, and reproduction in any medium, provided you give appropriate credit to the original author(s) and the source, provide a link to the Creative Commons license, and indicate if changes were made. The Creative Commons Public Domain Dedication waiver (http://creativecommons.org/publicdomain/zero/1.0/) applies to the data made available in this article, unless otherwise stated. 


\section{Background}

Chronic obstructive pulmonary disease (COPD) is an irreversible, but treatable disease that is characterized by airflow limitation and persistent respiratory symptoms [1]. The global prevalence of COPD is estimated at 12\% (95\% confidence interval, or CI, 8-15\%) among individuals aged 30 years or over [2].

The global burden of COPD is considered to be high [3]. In particular, results from a systematic review indicate that COPD is responsible for a large number of emergency room visits and hospitalizations, profoundly impacts patients' quality of life, and results in expensive total costs per COPD patient from both the patient and societal perspective [4].

To reduce COPD-related morbidity, COPD patients need to develop several self-management skills, including: using their inhalers correctly, monitoring the control of their disease, preventing and controlling exacerbations, and using breathing techniques [1].

Therapeutic patient education (TPE) is an active, evidence-based, and patient-centered process by which health care professionals, also referred to as educators, guide and support patients in developing these self-management skills [5]. When compared to usual care, TPE results in improvement of quality of life among COPD patients, as well as in reduction of dyspnoea and hospitalizations [6].

Nevertheless, not all TPE programs have a positive impact on COPD health outcomes. For instance, in 2012, a randomized controlled trial by Fan et al. [7] was terminated before its planned completion date, due to the excess mortality estimated within the participants allocated to TPE, compared to guideline-concordant usual care. Although a subsequent meta-analysis concluded that TPE does not result in an increased risk of mortality in patients with COPD [8], Fan et al. [7] were unable to explain why the number of deaths was higher in the TPE group than in the comparison group, nor were they able to assess the quality of TPE when reporting the results of their study. In this context, authors have hypothesized that benefits from TPE could depend on the performance of the educators and especially on the training that they received to deliver effective TPE interventions [9]. Hence, ensuring the optimal training of COPD educators is crucial.

Continuing education (CE) activities (including: lectures, conferences, seminars, workshops, symposia, and courses) have been widely used in order to improve health care professional practice and, subsequently, patient outcomes [10]. CE activities can be described through their learning objectives, activities, and assessments, and classified into six cognitive processes and four knowledge types according to the Revised Bloom's Taxonomy for Learning, Teaching, and Assessing [11]. Conceptually, to promote translation of knowledge into practice, the learning objectives of a particular CE activity should be classified into the higher-order cognitive processes [11]. The correspondence between the learning objectives, activities, and assessments is defined as alignment. Described as strong, weak, or misalignment, alignment ensures the following two characteristics: (1) the learning activities enable attendees to perform adequately in assessments, and (2) the results of the assessments reflect the achievement of the learning objectives [11].

$\mathrm{CE}$ activities can also be described through some components of a CE activity that have been reported to impact on health care professional performance [12-14] and patients' outcomes $[13,14]$. These components include the following:

(1) the number of attendees in a CE activity: small groups of $<10$ attendees might result in better educational outcomes than moderate-to-large groups of $\geq 10$ attendees [14];

(2) the format of the CE activity: an active learning format that includes role play simulations, case discussions, or opportunities to practice skills might result in better educational outcomes than a passive learning format that includes: lectures or presentations, with or without question and answer periods $[13,14]$;

(3) the organizational support [12].

Moore et al. [15] developed the Expanded Outcomes Framework for Planning and Assessing Continuing Medical Education Activities to evaluate the achievement of desired educational results. This framework includes several levels of assessment (Table 1). Based on this framework, our study will aim to compare the impact of two CE activities on TPE that target COPD educators. One CE activity will include a role-playing simulation and involve a small group of attendees (experimental group). The other CE activity will consist of a lecture on TPE that will be presented to a moderate-to-large group of attendees (comparison group).

Specifically, we will compare both activities in regard to the following educational outcomes: (1) satisfaction, (2) learning, (3) self-report of competence, (4) performance of the COPD educators who will attend either CE activity, and (5) outcomes of COPD patients who will meet the newly trained COPD educators for TPE after the CE activity.

As reported in other studies assessing satisfaction with a CE activity [16-19], we hypothesize that (1) satisfaction with the CE activity will be similar in the experimental and comparison groups immediately after the CE activity. In view of the fact that a small number of attendees and an active learning format have been reported to improve health care professional performance and patient outcomes [13, 14], we hypothesize that: (2) improvements in 
Table 1 The expanded outcomes framework for planning and assessing continuing medical education activities by Moore et al. [15]: Definitions

$\begin{aligned} & \text { Educational } \\ & \text { outcome }\end{aligned}$
$\begin{array}{ll}\text { Satisfaction } & \text { "The degree to which the expectations of the participants about the setting and delivery of the [CE] activity were met." } \\ \text { Learning } & \text { "The degree to which the participants state what the [CE] activity intended them to know [or] the degree to which participants } \\ \text { state how to do what the [CE] activity intended them to know how to do [it]." } & \text { "The degree to which participants show in an educational setting how to do what the [CE] activity intended them to be able } \\ \text { to do." } & \text { "The degree to which participants do what the [CE] activity intended them to be able to do in their practices." } \\ \text { Performance } & \text { "The degree to which the health status of patients improves due to changes in the practice behavior of participants." }\end{array}$
$\begin{aligned} & \text { Patient outcome } \\ & \text { Definitions }\end{aligned}$

Definitions are quoted from Moore et al. [15]

CE Continuing education

educators' learning before and after the CE activity will be greater in the experimental group (small group of educators + active learning format), compared to the comparison group (moderate-to-large group of educators + passive learning format), as will be (3) improvements in educators' self-reports of competence before and after the CE activity, and (4) educators' performance levels after the CE activity. Similarly, we believe that (5) improvements in patient outcomes before and after TPE will be greater in the experimental group (TPE delivered by educators who attended the experimental $\mathrm{CE}$ activity), compared to the comparison group (TPE delivered by educators who attended the comparison CE activity).

\section{Methods}

The following study protocol adheres to the SPIRIT guidelines [20].

\section{Study design}

We will conduct a pragmatic non-randomized controlled study using explanatory sequential mixed methods [21]. From June 2016 to October 2017, moderate-to-large groups of $\geq 10$ educators will participate in a lecture on TPE (comparison group). From November 2017, and thereafter, small groups of $<10$ educators will be involved in a CE activity on TPE that will include a role-play simulation (experimental group). In educators, quantitative and qualitative measurements will be undertaken before and after the CE activity. Four months after the CE activity, educators will provide COPD patients with TPE in their work settings. Measurements will be undertaken in COPD patients before and after TPE.

Our study was registered in ClinicalTrials.gov (NCT02870998) on March 15, 2016.

\section{Eligibility criteria}

All French-speaking educators (e.g. nurses, respiratory therapists, and other allied health professionals) who will attend either CE activity on TPE organized on behalf of the Quebec Respiratory Health Education Network in
June 2016, and thereafter, will be eligible to participate in the study. Most of these educators work in family medicine groups, local community service centers, or in hospitals, which include emergency departments. Physician-diagnosed COPD patients, who will meet the newly trained COPD educators for TPE after either CE activity, will be eligible to participate in the study.

\section{Interventions}

Educators will be allocated to a CE activity on TPE that will include a role-playing simulation and involve a small group of attendees (experimental group) or to a lecture on TPE that will be presented to a moderate-to-large group of attendees (comparison group). Hence, the CE activities differ in their number of participants and learning format.

Both CE activities will be similar in regard to their content and learning objectives. The content of the $\mathrm{CE}$ activities will pertain to TPE and the general learning objective of both $\mathrm{CE}$ activities can be described as: to be able to deliver effective TPE interventions to COPD patients. The specific learning objectives are adapted from the Canadian Network for Respiratory Care's National Certified Respiratory Educator Learning Objectives [22]. They are presented in Table 2.

The study coordinator (M.G.) will attend the CE activities to ensure adherence to intervention protocols.

\section{Experimental group: small groups of $<10$ educators attending a CE activity on TPE that will include a role-playing simulation}

In the experimental group, small groups of $\approx 6$ educators will participate in a seven-hour CE activity on TPE that will include a role-playing simulation. As part of the development phase of this activity, the learning activities and assessments were reviewed by experienced case managers $(n=4)$ and physicians $(n=2)$. On four occasions, the activity was pretested among both experienced and non-experienced educators ( $\mathrm{n} \approx 4$ per occasion). 
Table 2 Specific objectives of the two CE activities

1. To define TPE
To demonstrate TPE skills while:
a. Demonstrating how to take a patient's medical history
b. Demonstrating how to teach a patient to use an action plan
c. Demonstrating how to teach a patient to complete a symptom
diary form
d. Interpreting a patient symptom diary as to whether COPD
control is acceptable
e. Demonstrating how to teach a patient to use and maintain
medication delivery devices
f. Demonstrating pursued lip breathing techniques, diaphragmatic
breathing, controlled cough and forced expiration techniques,
and relaxation techniques
g. Performing a follow-up visit

These specific objectives are based on the Canadian Network for Respiratory Care's National Certified Respiratory Educator Learning Objectives [22] CE Continuing education, COPD Chronic obstructive pulmonary disease, TPE Therapeutic patient education

Before the activity, educators will be asked to read a necessary online document on TPE. Learning activities will include the following:

- a lecture on core concepts of TPE (1.5 h; passive learning format);

- a group discussion about TPE (0.5 h; active learning format);

- demonstrations and case studies on how to demonstrate TPE skills while taking a COPD patient's medical history and interpreting an action plan (two hours; passive and active learning format);

- demonstrations and practices of how to ensure TPE skills while teaching a patient to use and maintain medication delivery devices (one hour; passive and active learning format);

- a role-playing simulation relating to a COPD patient's initial and follow-up TPE visits (two hours; active learning format).

As part of the evaluation of the CE activity, participants will be asked the following two requests: (1) to fill a questionnaire assessing their comprehension of the core concepts of TPE, and (2) to perform an objective structured clinical examination with a standardized patient. Hence, the learning objectives, activities, and assessments will be strongly aligned, according to the Revised Bloom's Taxonomy [11] (see Fig. 1a).

\section{Comparison group: moderate-to-large group of $\geq 10$ educators attending a lecture on TPE}

In the comparison group, moderate or large groups of $\approx 12-25$ educators will participate in a seven-hour lecture on TPE. Although the animator will encourage educators' active participation during the presentation, learning will be mostly passive, because a lecture format does not easily allow for an attendee-animator dialogue [23]. The evaluation of this CE activity will include a questionnaire that assesses the memorization of TPE concepts and procedures. Based on the Revised Bloom's Taxonomy [11], there will be a weak alignment or a misalignment of the learning objectives, activities, and assessments (see Fig. 1b).

\section{Educational outcomes Satisfaction}

Educators will complete a questionnaire assessing the extent to which their expectations about the CE activity were met. The questionnaire (@Formaeva, an organization that develops evaluation tools to assess training activities; additional information available at: https://www.formaeva.com/) evaluates the degree to which participants appreciate the activity ( 1 item, $1=$ absolutely no, $10=$ absolutely yes) and rate its upstream preparation ( $n=3$ items), organization ( $n=2$ items), content ( $n=4$ items), animation ( $n=3$ items), structure ( $n=2$ items), and usefulness $(n=2$ items), using a 5-point Likert scale (either $1=$ strongly disagree, 5 = strongly agree or $1=$ too short, 5=too long). Two open-ended questions assess the CE activity strengths and areas of improvement. Formaeva can provide the questionnaire to the reader upon request.

\section{Learning}

Change from baseline knowledge about TPE will be assessed among educators, who will be asked to complete pre- and post-tests of knowledge about TPE. The questionnaire, comprising eight open-ended questions aligned with the specific objectives of the CE activity (please refer to Additional file 1). Questions were based on current literature on TPE $[5,24]$. The questionnaire was pretested among formerly trained educators $(n=6)$ and experienced respiratory educators $(n=3)$ to ensure its face validity. It was also reviewed by experts on TPE $(n=1)$ and $\operatorname{CE}(n=1)$, and by the CE activity animators $(n=2)$ for preliminary content validity assessment. The overall score ranges from 0 to 25 . A higher score indicates greater knowledge.

\section{Self-report of competence}

Change from baseline self-report of competence will be assessed in educators using a questionnaire (@Formaeva). This questionnaire measures pre-/post-activity self-report of competence in regard to the following three CE activity objectives: (1) to define TPE, (2) to demonstrate TPE skills while teaching a patient to use and maintain medication delivery devices, and (3) to deliver effective TPE intervention. Again, Formaeva can provide the questionnaire to the reader upon request. 


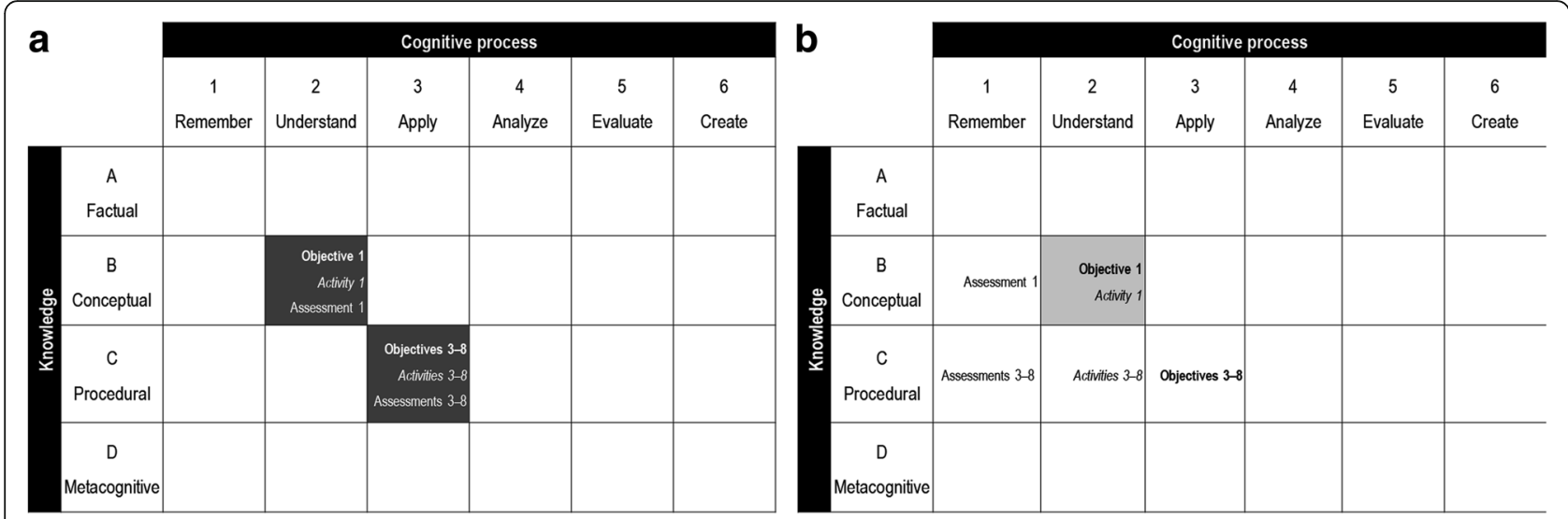

Fig. 1 Alignment of the objectives, learning, and evaluation activities in the experimental and comparison groups. In accordance with the Revised Bloom's Taxonomy [11], dark shading indicates that there is a strong alignment between the objectives, learning activities, and assessment (all present in the same cell), as in the experimental group (a). Light shading indicates that there only is a weak alignment. When the objectives, activities, and assessments are not in the same cell, there is a misalignment, as in the comparison group (b)

\section{Performance}

We will measure educators' post-CE activity performance in delivering high-quality TPE interventions to a real patient by using a published effective TPE rating scale $[25,26]$. Twenty operationally defined teaching behaviors assess the following four effective TPE skills: (1) interpersonal skills $(n=3$ items; e.g. showing respect for patients), (2) presentation skills ( $n=9$ items; e.g. stating learning objectives), (3) essential teaching functions ( $n=4$ items; e.g. providing patients with feedback), and (4) adherence counseling strategies $(n=4$ items; e.g. negotiating treatment plans) [25]. Each item is scored on a 4-point scale $(0=$ absent, $1=$ poor, $2=$ adequate $/$ good, $3=$ excellent use of the skill). Item scores are averaged to calculate a subscale score (range $0-3$, higher scores indicating greater effective TPE skills) [25].

\section{Patient outcomes: health status and health resource utilization}

After the completion of either CE activity, the newly trained educators will deliver one or several TPE interventions to COPD patients in their professional practice. Among these COPD patients, we will assess change from baseline health status and health resource utilization.

Health status Health status will be measured using the activity and impact components of the COPD-specific version of the St. George's Respiratory Questionnaire (SGRQ-C) [27] and the COPD Assessment Test (CAT). Validated French-Canadian versions will be used [28]. Both the SGRQ-C and the CAT are suitable for evaluating COPD patient health status in recent times [27, 29]. The impact dimension of the SGRQ-C will be considered as our primary patient health outcome.
The activity and impact components of the SGRQ-C are comprised of 13 and 20 closed-ended items, respectively [27]. For each component, a weighted score, ranging from 0 (perfect health) to 100 (most severe status), is derived [27]. A difference in SGRQ-C score equivalent to 4 points is considered clinically significant [30]. The SGRQ-C has been developed from the original SGRQ using Rasch analyses [27]. The SGRQ has been previously validated, using correlations with appropriate comparison measures [31].

The CAT is an 8-item instrument that measures health status using 5-point Likert scales [29]. Response options are summed, and the overall CAT score ranges from 0 to 40 (lower scores are better) [29]. The minimal clinically important difference in the CAT score is -2 [32]. The CAT has been validated using Rasch analyses [33]. Its internal consistency has been shown to be excellent, and its test/re-test reliability has been shown to be good [33]. It has demonstrated responsiveness to change [34].

Health education impacts The eight independent dimensions of the Health Education Impact Questionnaire (heiQ), a 40-item questionnaire developed to evaluate proximal TPE outcomes [35], will be measured. These dimensions are: (1) health-directed behaviors, (2) skill and technique acquisition, (3) self-monitoring and insight, (4) positive and active engagement in life, (5) constructive attitudes and approaches, (6) health services navigation, (7) social integration and support, and (8) emotional well-being. Each item of the heiQ uses a 4-point Likert scale $(1=$ strongly disagree, $4=$ strongly agree, except for the eighth dimension, which uses a reversed scale) [35]. Response options are averaged, and higher scores are better [35]. The heiQ development was based on a Program Logic Model, Concept Mapping, and interviews with stakeholders [35]. Item response theory and structural equation 
modeling were used to assess its psychometric properties [35]. The heiQ was found to have high construct validity and to be reliable [35]. In this study, we will use the Canadian-French version of the heiQ [36].

Health resource utilization The number of unscheduled doctor visits, emergency room visits, and hospitalizations in the six preceding months will be measured using three items derived from the Survey on Living with Chronic Diseases in Canada (SLCDC) [37] and available at: http://www23.statcan.gc.ca/imdb-bmdi/ instrument/5160_Q6_V1-eng.pdf. To ensure the face validity of the SLCDC, questions were framed in collaboration with respiratory experts and qualitatively tested using face-to-face interviews [37].

\section{Confounding, professional, clinical, and sociodemographic variables}

Determinants of educational outcomes identified a priori will be measured (see Table 3). To characterize study participants, we will collect data on attendees' jobs, undergraduate studies, the number of years of professional practice, and former participation in $\mathrm{CE}$ activities, using a standardized form. In COPD patients, we will measure disease severity that is classified by symptoms and disability [38], along with marital status, highest attained level of education, and annual family income, using items derived from the Quebec Survey on Cardiovascular Health (QSCH) [39].

\section{Participant timeline}

Figure 2 illustrates the schedule for enrollment, interventions, and assessments. The measurement time points have been chosen in accordance with the $E x$ panded Outcomes Framework for Planning and Assessing Continuing Medical Education Activities [15] (e.g. satisfaction and self-report of competence are measured immediately after a CE activity) and feasibility issues (e.g. time for institutional feasibility approval for performance and patient outcome assessments). As illustrated in Fig. 2a, educators will be enrolled and will be asked to complete baseline measurements on the morning of the $\mathrm{CE}$ activity $\left(t_{-1}\right.$, educators $)$. Among educators, post-activity measurements will be undertaken immediately after the $\mathrm{CE}$ activity $\left(t_{1}\right.$, educators $)$, for satisfaction and self-report

Table 3 List of possible confounding factors

\begin{tabular}{|c|c|c|c|}
\hline Educational outcome & Confounding variable & Units, categories, or range & Instrument \\
\hline \multirow{4}{*}{$\begin{array}{l}\text { Educators' satisfaction } \\
\text { Educators' learning } \\
\text { Educators' competence } \\
\text { Educators' performance }\end{array}$} & Age [12] & in years & Standardized form \\
\hline & \multirow[t]{2}{*}{ Level of education [12] } & $<$ University & \multirow[t]{2}{*}{ Standardized form } \\
\hline & & $\geq$ University & \\
\hline & $\begin{array}{l}\text { Motivation to participate in } \\
\text { the CE activity [12] }\end{array}$ & Score: 0-6 & Adapted from the MSLQ [58] \\
\hline \multirow[t]{17}{*}{ COPD patients' outcomes } & Smoking history [59] & in packs-year & SLCDC [37] \\
\hline & Dyspnea [60] & $\begin{array}{l}\text { Medical Research Council dyspnea } \\
\text { scale, grade: } 1-5\end{array}$ & SLCDC [37] \\
\hline & \multirow[t]{2}{*}{ Social support [59] } & Yes & \multirow[t]{2}{*}{ SLCDC [37] } \\
\hline & & No & \\
\hline & \multirow[t]{2}{*}{ Comorbidity [60] } & Yes & \multirow[t]{2}{*}{ SLCDC [37] } \\
\hline & & No & \\
\hline & \multirow[t]{2}{*}{ Respiratory tract infections [59] } & Yes & \multirow[t]{2}{*}{ SLCDC [37] } \\
\hline & & No & \\
\hline & \multirow[t]{2}{*}{ Body mass index [60] } & $<21$ & \multirow[t]{2}{*}{ QSCH [39] } \\
\hline & & $\geq 21 \mathrm{~kg} / \mathrm{m}^{2}$ & \\
\hline & Age [61], & in years & QSCH [39] \\
\hline & \multirow[t]{2}{*}{ Gender [62] } & Women & \multirow[t]{2}{*}{ QSCH [39] } \\
\hline & & Men & \\
\hline & \multirow{2}{*}{$\begin{array}{l}\text { Previous exacerbations in the six } \\
\text { preceding months }[59,60]\end{array}$} & Yes & \multirow{2}{*}{$\begin{array}{l}\text { Telephone interviewer-administered } \\
\text { questionnaire [63] }\end{array}$} \\
\hline & & No & \\
\hline & Levels of anxiety $[60,64]$ & Score: $0-21$ & HADS [65] \\
\hline & Levels of depression $[60,64]$ & Score: 0-21 & HADS [65] \\
\hline
\end{tabular}

Depending on the educational outcome, these variables will be measured in educators or in COPD patients HADS Hospital Anxiety and Depression Scale, MSLQ Motivated Strategies for Learning Questionnaire, QSCH Quebec Survey on Cardiovascular Health, SLCDC Survey on Living with Chronic Diseases in Canada 
of competence, at 1-month post-activity $\left(t_{2}\right.$, educators $)$, for learning, and at 2-month post-activity $\left(t_{3}\right.$, educators $)$, for performance. Interviews will be conducted among educators at ( $t_{4}$, educators), after quantitative measurements (details on the interviews will be given in section "Interviews with educators" below).

Four months after the $\mathrm{CE}$ activity, newly trained educators will deliver TPE to COPD patients. In COPD patients, measurements will be undertaken prior to TPE, at $\left(t_{-1}\right.$, patients $)$, and six months after TPE, at $\left(t_{1, \text { patients }}\right)$.

\section{Sample sizes}

The size of our sample of educators was calculated on the basis of our fourth study hypothesis, that predicted that post-CE activity performance levels will be higher in the experimental group compared to the other [13, 14]. In a previous study, educators were found to have a score of 0.89 on the effective TPE rating scale [25]. We think that the educators of the comparison group will also have this score. We expect the educators of the experimental group to have a score of 2.00 , that is considered as good on this scale [25]. Therefore, we calculated that a sample size of seven educators per group was required to detect a group difference of 1.11 point (standard deviation, or $\mathrm{SD}=0.63$; type II error $=0.20$, or $80 \%$ power; type I error $=0.05$; two-sided test).

The size of our sample of COPD patients was calculated on the basis of our fifth study hypothesis, that predicted that patient outcomes will be further enhanced in COPD individuals who will meet the newly trained COPD educators of the experimental group, compared to the other $[13,14]$. We expect the COPD patients, who will meet the newly trained COPD educators of the comparison group, to experience a change at 6-month follow-up equivalent to -2 points on the impact dimension of the SGRQ-C, similar to the patients who were allocated to a previous usual care intervention [40]. Consistent with previous results [40], we expect the COPD patients, who will meet the newly trained COPD educators of the experimental group, to make an improvement equivalent to +9 points. Using the SAS generalized estimating equation macro for controlled clinical trials with repeated measurements on the same individuals [41], we estimated that a sample size of 94 patients per group was required to detect a between-group difference of 11 points $(\mathrm{SD}=19$; type II error $=0.20$, or $80 \%$ power; type I error $=0.05$; two-sided test).

To account for possible losses to follow-up, to ensure Gaussian distributions, and because it was considered as feasible to recruit $\approx 5$ COPD patients per educator, we hope to recruit 25 educators per group and 125 COPD patients per group ( $\approx 5$ patients per educator). The $C E$ activities will be delivered on several occasions from June 2016, and thereafter, to achieve the required sample sizes of both educators and patients.

\section{Assignment of interventions}

The CE activities will be organized on behalf of the Quebec Respiratory Health Education Network twice per year, either in Quebec City or Montreal, Quebec, Canada. Upon request, the Quebec Respiratory Health Education Network may decide to schedule additional CE activities outside these two cities. Educators, who will participate in the $\mathrm{CE}$ activities held from June 2016 to October 2017, will be allocated the comparison group, whereas those attending the activity after November 2017 will be assigned to the experimental group.

\section{Blinding}

Data analysts will be blinded to interventions, along with study participants, who will not be aware that there will be two different $\mathrm{CE}$ activities.

\section{Recruitment}

Before either CE activity, the study coordinator (M.G.) will invite all educators to participate in the study and will be in charge of their recruitment. Four months after the CE activity, the newly trained educators will invite their COPD patients to participate in the study. Educators will communicate the names and contact information of the COPD patients who will accept the invitation to take part in the study to the study coordinator. Then, trained research assistants will be responsible for the recruitment of COPD patients. We plan to stop the recruitment when we will reach the targeted sample sizes of both educators and COPD patients.

\section{Data collection methods}

Questionnaires measuring educators' satisfaction, learning (baseline/post-activity knowledge), competence, and confounding factors will be self-administered. For satisfaction, baseline knowledge, pre-/post-activity self-report of competence, and confounding factors, data will be collected on the CE activity site. Data on post-activity knowledge will be collected on the educators' work site. We will send reminders to educators who will not return the post-activity knowledge questionnaire.

To measure performance for each educator, we will videotape one TPE intervention delivered to a real COPD patient in each educator's professional practice. The study coordinator will send the camera to the educator by mail. Upon reception of the camera, the educator will invite the first patient to whom he or she will deliver TPE to participate in the study. If the patient refuses, then the educator will ask the following patient, and so on. We will ask educators to place a GoPro HERO Session ${ }^{\text {Tw }}$ camera (GoPro, San Mateo, CA, USA) on their desk. The camera has the 
a

\begin{tabular}{|c|c|c|c|c|c|c|}
\hline & Enrollment & CE activity & Immediately after & 1-month post & 2-month post & 5-month post \\
\hline TIMEPOINT & $-t_{1}$, educators & $t_{0, \text { educators }}$ & $t_{1, \text { educators }}$ & $t_{2, \text { educators }}$ & $t_{3, \text { educators }}$ & $t_{4, \text { educators }}$ \\
\hline $\begin{array}{l}\text { ENROLLMENT: } \\
\text { Eligibility screen }\end{array}$ & $x$ & & & & & \\
\hline Informed consent & $x$ & & & & $x$ & \\
\hline Allocation & & $x$ & & & & \\
\hline $\begin{array}{l}\text { INTERVENTION: } \\
\text { Educators attend either CE activity }\end{array}$ & & $x$ & & & & \\
\hline $\begin{array}{l}\text { ASSESSMENTS } \\
\text { Sociodemographic and } \\
\text { professional characteristics }\end{array}$ & $x$ & & & & & \\
\hline$\circ$ Confounding variables & $x$ & & & & & \\
\hline - Satisfaction & & & $x$ & & & \\
\hline$\circ \quad$ Learning & $x$ & & & $x$ & & \\
\hline - Self-report of competence & $x$ & & $x$ & & & \\
\hline - Performance & & & & & $x$ & \\
\hline - Interview & & & & & & $x$ \\
\hline
\end{tabular}

b

\begin{tabular}{|c|c|c|c|c|}
\hline & CE activity & 4-month post-CE activity & TPE & $\begin{array}{c}\text { 10-month post CE activity, } \\
\text { or 6-month post-TPE }\end{array}$ \\
\hline TIMEPOINT & & $t_{-1, \text { patients }}$ & $t_{0, \text { patients }}$ & $t_{1, \text { patients }}$ \\
\hline $\begin{array}{l}\text { ENROLLMENT: } \\
\text { Eligibility screen }\end{array}$ & & $x$ & & \\
\hline Informed consent & & $x$ & & \\
\hline Allocation & & $x$ & & \\
\hline $\begin{array}{l}\text { INTERVENTIONS: } \\
\text { Educators attend either CE activity }\end{array}$ & $x$ & & & \\
\hline Educators deliver TPE in COPD patients & & & $x$ & \\
\hline ASSESSMENTS & & & & \\
\hline $\begin{array}{l}\text { - COPD patients } \\
\circ \quad \text { Sociodemographic and clinical } \\
\text { characteristics }\end{array}$ & & $x$ & & \\
\hline - Confounding variables & & $x$ & & \\
\hline - Patient outcomes & & $x$ & & $x$ \\
\hline
\end{tabular}

Fig. 2 SPIRIT flow diagram: Educators' and patients' timelines for the schedule of enrolment, interventions, and assessments Derived from the SPIRIT statement [57]. a. Educator timeline Educators will be enrolled and will be asked to complete baseline measurements on the morning of the CE activity $\left(t_{-1}\right.$, educators $)$. Post-CE activity measurements will be undertaken immediately after the CE activity $\left(t_{1}\right.$, educators $)$, for satisfaction and

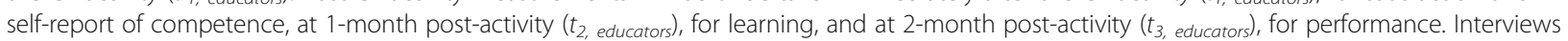
will be conducted among educators 5 months after the CE activity $\left(t_{4}\right.$, educators $)$. b. Patient timeline. Four months after attending either CE activity, educators will perform TPE in COPD patients. Patient outcomes will be measured prior to TPE, at $\left(t_{-1,}\right.$, patients). Six months later, at $\left(t_{l}\right.$, patients $)$, post-TPE measurements will be undertaken in COPD patients

height of $38 \mathrm{~mm}$, the width of $38 \mathrm{~mm}$, and the depth of $36.4 \mathrm{~mm}$. It starts recording when pushing a single button and captures up to a 2-h ultra-wide field of view video in .mp4 file format.

Data on COPD patient health status, resource utilization, and confounding factors will be collected via telephone interviews with trained research assistants. The SLCDC is an interviewer-administered instrument. Previous studies have shown that the SGRQ and the CAT produce similar results when interviewer-administered [42, 43]. The heiQ, along with the Hospital Anxiety and Depression Scale (HADS), used to measure two confounding factors, will be mailed to patients and self-administered at each of the patients' homes. Both the heiQ and the HADS could be interviewer-administered, upon request, to avoid missing data. 


\section{Data management}

We will perform independent double data entry for numeric data (satisfaction, self-report of competence, patient outcomes, confounding factors). Two individuals will independently rate attendees' learning and performance. When attributing knowledge scores, independent raters will be blinded to the measurement time point. They will score videotapes in random order. We will calculate interrater reliability using an intra-class correlation coefficient $[44,45]$. Consensus will resolve disagreements. If necessary, a third reviewer will be consulted. All data will be stored on a secure server to prevent unauthorized access and loss of participant data.

\section{Statistical analyses}

Data will be analyzed by intention-to-treat [46]. The experimental group will be compared to the comparison group for all statistical analyses. To compare participant characteristics, we will use $x^{2}$ test for binary outcomes and $t$-test for continuous outcomes. In educators, we will compare post-CE activity satisfaction and performance scores using multivariate linear regression models [47]. We will compare, in educators, change from baseline knowledge scores and change from baseline self-report of competence scores, and, in COPD patients, change from baseline patient outcome scores or counts, using generalized linear or Poisson mixed models with appropriate interaction terms (group $\times$ time) [48]. We will assume a specified form of covariance structure among the two repeated measurements (knowledge: $t_{2}$, educators versus $t_{-1}$, educators; competence: $t_{1}$, educators versus $t_{-1}$, educators; COPD patient outcomes: $t_{1 \text {, patients }}$ versus $t_{-1}$, patients). We will assume a specified form of covariance structure among the two repeated measurements (knowledge: $t_{2}$, educators versus $t_{-1}$, educators; competence: $t_{1}$, educators versus $t_{-1}$, educators; COPD patient outcomes: $t_{1}$, patients versus $t_{-1}$, patients). Estimates and standard errors will be based on a restricted likelihood function given the observed data. Specifying an unstructured covariance matrix, we will handle possible missing values at follow-up [49]. Depending on the variable type, we will calculate differences in means and counts with corresponding 95\% confidence intervals [47, 48]. Model assumptions will be assessed. Determinants of educational outcomes identified a priori will be included in statistical models if they result in a $>10 \%$ change in the differences in means and counts [50]. We will examine the residuals to assess goodness-of-fit $[47,48]$. We also plan to perform independent variable transformations if model assumptions are not met [51] or to use ordinal or binomial regression models. We will use an up-to-date version of SAS (Cary, NC, USA) to conduct all statistical analyses and two-sided $p$-values with $\alpha \leq 0.05$ level of significance for all tests.

\section{Interviews with educators}

We will conduct telephone interviews with educators of both the experimental and comparison groups to further explain our quantitative results [21]. We will purposefully select educators for interviews, based, for instance, on their performance scores or their professional characteristics. Based on the levels of assessment of the Expanded Outcomes Framework for Planning and Assessing Continuing Medical Education Activities [15], we will develop a semi-structured interview guide. The guide will also question the educators about the organizational support that they receive in their work setting in regard to TPE intervention delivery.

\section{Qualitative analyses}

We will audiotape the interviews, transcribe interviews verbatim, and randomly check selected extracts of transcripts to ensure that there are no mistakes [21]. We will import data to QSR NVivo 11 software $^{\circ}$ and conduct content analysis [52]. Two members of our team will independently read and code three interviews' transcripts, using an inductive approach [52]. They will compare their coding and debrief in order to develop the first version of the codebook. Based on this first version, they will independently assign codes to the data of the other interviews. We will compare their codes, resolve disagreements by consensus, and refine the codebook. Codes will be sorted into categories and the categories into themes. We will conduct interviews until saturation is reached [21]. Findings from the final analysis will be presented to educators to determine their accuracy [21].

\section{Integration}

In the discussion section of the published articles, results will be integrated in order that qualitative findings help expand or explain the quantitative ones [21].

\section{Dissemination}

We plan to communicate our results to the Quebec Respiratory Health Education Network, which designed and delivers the CE activities. We will also communicate them to study participants, Quebec Ministry of Health, and researchers, via publications and presentations in local, provincial, national, and international meetings. We intend to have no publication restriction.

\section{Discussion}

Based on the framework by Moore et al. [15], our study will aim to compare the impacts of two CE activities on TPE that target COPD educators in regard to five educational outcomes. 


\section{Strengths}

Previous pre/post studies [53-55] have evaluated the impact of CE activities targeted at COPD educators on some, but not all educational outcomes, as defined by Moore et al. [15]. None of these previous studies evaluated educators' organizational support in regard to TPE intervention delivery, even though the organizational support is a major factor to consider when assessing the impact of a CE activity [12]. To the best of our knowledge, this study is the first controlled mixed methods study to compare the impact of two CE activities on TPE in regard to five educational outcomes, while qualitatively documenting how educators are supported by their organization.

In contrast to previous studies [53-55], our study will objectively assess educators' learning, using pre- and post-tests of knowledge, as suggested by Moore et al. [15]. Our study will also evaluate educators' performance levels in delivering high-quality TPE interventions, based on observation measures of performance in each of the educator's professional practice.

\section{Limitations}

We expect our study to have limitations. First, non-differential measurement errors might occur, because:

(1) we designed an ad hoc assessment test to measure educators' learning, due to the fact that we wanted the knowledge questionnaire to be aligned with the learning objectives of both $\mathrm{CE}$ activities;

(2) we will assess educators' performance levels in delivering high-quality TPE education to a single real patient, instead of videotaping educator encounters with both real and standardized patients, as it has been suggested [56];

(3) educators' performance will only be measured after the CE activity;

(4) we will only perform a subjective assessment of changes in patient outcomes, due to organizational constraints.

Second, because the study is a pragmatic one, we expect that there could be some heterogeneity between the TPE interventions that will be delivered by each of the educators' professional practice. Because what is referred to TPE may differ from a setting to another, heterogeneity is likely to have an impact on changes from baseline patient outcomes. Nevertheless, interviews with attendees will help to describe the implementation of TPE programs better, and, in turn, to explain our study results better.

Finally, we will compare, in the present study, two CE activities that will include two independent components: (1) the number of attendees $(<10$ versus $\geq 10)$ and (2) the learning format (active versus passive). In contrast to a factorial design, our study design will not allow us to understand the effect of each independent component upon the educational outcomes.

\section{Perspectives}

To the best of our knowledge, our study is the first controlled mixed methods study to compare the impact of two CE activities on TPE in regard to five educational outcomes. The experimental CE activity was designed to promote the achievement of higher-order cognitive processes and align its learning objectives, activities, and assessments. We believe this study will serve as a model for evaluating CE activities on TPE. Results from this study could increase COPD educators' performance levels in delivering effective TPE interventions, and, in turn, COPD patient outcomes.

\section{Additional file}

Additional file 1: Questionnaire on attendees' learning. The questionnaire on attendees' learning comprises eight open-ended questions aligned with the CE activity specific objectives. A professional translator translated the items from French to English. (DOCX $46 \mathrm{~kb}$ )

\section{Abbreviations}

CAT: COPD Assessment test; CE: Continuing education; Cl: Confidence interval; COPD: Chronic obstructive pulmonary disease; HADS: Hospital anxiety and depression scale; heiQ: Health education impact questionnaire; MSLQ: Motivated strategies for learning questionnaire; QSCH: Quebec survey on cardiovascular health; SD: Standard deviation; SGRQ-C: COPD-specific version of the St. George's respiratory questionnaire; SLCDC: Survey on living with chronic diseases in Canada; TPE: Therapeutic patient education

\section{Acknowledgements \\ The authors wish to thank Marie-Ève Boulay, M.Sc., Françoise Proust, Ph.D., and Julie Turmel, Ph.D. for assistance in revising the study protocol. We are grateful to Erica Pridoehl, M.Ed. for editing the English manuscript. The authors thank Barbara Pattison, trad.a. for translating the questionnaire used to measure attendees' learning from French to English.}

\section{Funding}

The Laval University Knowledge Translation, Education and Prevention Chair in Respiratory and Cardiovascular Health has received funding from GlaxoSmithKline through its Medical Education Support Program for the development, deployment, and evaluation of the educational component (please refer to http://ca.gsk.com/en-ca/healthcare-professionals/independentmedical-education/). The present study is funded by Dr. Louis-Philippe Boulet's local funds.

\section{Availability of data and materials}

We plan to include all quantitative data generated or analyzed during this study in the published articles and their supplementary information files. Audio-visual datasets generated or analyzed during the current study will not be publicly available due to confidentially issues.

\section{Authors' contributions}

All authors contributed to the study design. MG wrote the initial draft and $J M, S L, C H, P C, J B$, and $L P B$ revised it for important intellectual content. All authors have given final approval of the version to be published and agree to be accountable for all aspects of the work.

Authors' information

M.G. will coordinate the present research project as part of her PhD thesis. 


\section{Ethics approval and consent to participate}

The study, including the French version of the protocol (dated June 27, 2016), has been approved by the Quebec Heart and Lung Institute Institutional Ethics Committee (MP-10-2016-2591). Any protocol amendments will be approved by the Quebec Heart and Lung Institute research ethics committee. The study coordinator (M.G.) will be responsible for communicating any of these amendments to coinvestigators and study participants.

We will obtain implied informed consent from educators who participate in the satisfaction and learning assessments.

Before videotaping TPE interventions, we will ask educators for written informed consent, whereas COPD patients, who will not be seen on the videos, will provide verbal informed consent.

Educators will also provide written informed consent to participate in interviews

Before patient outcome assessments, we will obtain verbal informed consent from COPD patients.

The consent form and other related documentation given to participants and authorized surrogates can be obtained upon request from the Quebec Heart and Lung Institute Institutional Ethics Committee at: gur@criucpq.ulaval.ca.

\section{Consent for publication}

We will assure confidentiality by giving all participants a unique identifier. We will remove any potentially identifiable information prior to reporting and publishing our findings. We will obtain consent to publish from the participant to report individual data.

\section{Competing interests}

The authors alone are responsible for the content and writing of this paper The Laval University Knowledge Translation, Education and Prevention Chair in Respiratory and Cardiovascular Health is supported by unrestricted grants from AstraZeneca. The Chair has received funding from GlaxoSmithKline for the development and deployment of the educational component. The program funds will not be used in connection with the research. The funding body has no role in the study design, collection, analysis or interpretation of data. The publication of our study results will not be contingent on our sponsor's approval or censorship of the manuscript. M.G. considers having no conflict of interest, but wishes to declare what could be perceived as potential conflicts of interest. Conference (honorarium): AstraZeneca. J.M., S.L., C.H., P.C., and J.B. declare that they have no competing interests in this work. L.P.B. considers having no conflict of interest, but wishes to declare what can be perceived as potential conflicts of interest. Advisory Boards: GlaxoSmithKline, Novartis. Conferences (honoraria): AstraZeneca, GlaxoSmithKline, Merck, Novartis. Sponsorship for investigator-generated research: AstraZeneca, GlaxoSmithKline, Merck Frosst, Schering. Sponsorship for research funding for participating in multicenter studies: AllerGen, Altair, Amgen, Asmacure, AstraZeneca, Boehringer-Ingelheim, Genentech, GlaxoSmithKline, Novartis, Ono Pharma, Pharmaxis, Schering, Wyeth. Support for the production of educational materials: AstraZeneca, GlaxoSmithKline, Merck Frosst, Boehringer-Ingelheim, Novartis. Organizational: Chair of the Global Initiative for Asthma (GINA) Guidelines Dissemination and Implementation Committee, Knowledge Translation, Education and Prevention Chair in Respiratory and Cardiovascular Health, Member of the Executive Committee of Interasma (Global Asthma Organization)

\section{Publisher's Note}

Springer Nature remains neutral with regard to jurisdictional claims in published maps and institutional affiliations.

\footnotetext{
Author details

${ }^{1}$ Knowledge Translation, Education and Prevention Chair in Respiratory and Cardiovascular Health, Laval University, Quebec City, QC, Canada. ${ }^{2}$ Quebec Heart and Lung Institute, Laval University, Quebec City, QC, Canada. ${ }^{3}$ Population Health and Optimal Health Practices Research Unit, CHU de Quebec Research Center, Quebec City, QC, Canada. ${ }^{4}$ Faculty of Pharmacy, Laval University, Quebec City, QC, Canada. ${ }^{5}$ Faculty of Education, Laval University, Quebec City, QC, Canada. ${ }^{6}$ Quebec Respiratory Health Education Network, Quebec City, QC, Canada. ${ }^{7}$ Respiratory Epidemiology and Clinical Research Unit, Research Institute of the McGill University Health Center, McGill University, Montreal, QC, Canada. ${ }^{8}$ Faculty of Medicine, McGill
}

University, Montreal, QC, Canada. ${ }^{9}$ Faculty of Medicine, Laval University, Quebec City, QC, Canada.

\section{Received: 8 May 2017 Accepted: 8 June 2018}

Published online: 18 June 2018

\section{References}

1. The Global Strategy for the Diagnosis Management and Prevention of COPD. Global Initiative for Chronic Obstructive Lung Disease (GOLD) 2017. http://goldcopd.org. 2017. Accessed 22 Feb 2018.

2. Adeloye D, Chua S, Lee C, Basquill C, Papana A, Theodoratou E, et al. Global and regional estimates of COPD prevalence: systematic review and metaanalysis. J Glob Health. 2015;5:020415.

3. Lopez-Campos JL, Abad Arranz M, Calero-Acuna C, Romero-Valero F, Ayerbe-Garcia R, Hidalgo-Molina A, et al. Guideline adherence in outpatient clinics for chronic obstructive pulmonary disease: results from a clinical audit. PLoS One. 2016:11:e0151896.

4. Dang-Tan T, Ismaila A, Zhang S, Zarotsky V, Bernauer M. Clinical, humanistic, and economic burden of chronic obstructive pulmonary disease (COPD) in Canada: a systematic review. BMC Res Notes. 2015;8:464.

5. Haute Autorité de santé. Structuration d'un programme d'éducation thérapeutique du patient dans le champ des maladies chroniques. SaintDenis La Plaine: HAS; 2007.

6. Zwerink M, Brusse-Keizer M, van der Valk PD, Zielhuis GA, Monninkhof EM, van der Palen J, et al. Self management for patients with chronic obstructive pulmonary disease. Cochrane Database Syst Rev. 2014;3:Cd002990.

7. Fan VS, Gaziano JM, Lew R, Bourbeau J, Adams SG, Leatherman S, et al. A comprehensive care management program to prevent chronic obstructive pulmonary disease hospitalizations: a randomized, controlled trial. Ann Intern Med. 2012;156:673-83.

8. Peytremann-Bridevaux I, Taffe P, Burnand B, Bridevaux PO, Puhan MA. Mortality of patients with COPD participating in chronic disease management programmes: a happy end? Thorax. 2014;69:865-6.

9. Bourbeau J. Integrated disease management for adults with chronic obstructive pulmonary disease. BMJ. 2014;349:g5675

10. Vaughn HT, Rogers $J$, Freeman JK. Does requiring continuing education units for professional licensing renewal assure quality patient care? Health Care Manag (Frederick). 2006;25:78-84.

11. Anderson LW, Krathwohl DR, Bloom BS. In: Abridged, editor. A taxonomy for learning, teaching, and assessing : a revision of Bloom's taxonomy of educational objectives. New York: Longman; 2001.

12. Francke AL, Garssen B, Huijer Abu-Saad H. Determinants of changes in nurses' behaviour after continuing education: a literature review. J Adv Nurs. 1995;21:371-7.

13. Mansouri M, Lockyer J. A meta-analysis of continuing medical education effectiveness. J Contin Educ Heal Prof. 2007;27:6-15.

14. Forsetlund L, Bjorndal A, Rashidian A, Jamtvedt G, O'Brien MA, Wolf F, et al. Continuing education meetings and workshops: effects on professional practice and health care outcomes. Cochrane Database Syst Rev. 2009;2:CD003030.

15. Moore DE Jr, Green JS, Gallis HA. Achieving desired results and improved outcomes: integrating planning and assessment throughout learning activities. J Contin Educ Heal Prof. 2009;29:1-15.

16. Jones JM, Papadakos J, Bennett C, Blacker S, Catton P, Harth T, et al. Maximizing your patient education skills (MPES): a multi-site evaluation of an innovative patient education skills training course for oncology health care professionals. Patient Educ Couns. 2011;84:176-84

17. Murray MA, Stacey D, Wilson KG, O'Connor AM. Skills training to support patients considering place of end-of-life care: a randomized control trial. J Palliat Care. 2010;26:112-21.

18. Shapiro M, Morey J, Small S, Langford V, Kaylor C, Jagminas L. Simulation based teamwork training for emergency department staff: does it improve clinical team performance when added to an existing didactic teamwork curriculum? Qual Saf Health Care. 2004;13:417-21.

19. Côté J, Boulet $L$, Boutin $H$, Leblanc $P$, Laviolette $M$, Rouleau M, et al. An asthma education program for health professionals. J Allergy Clin Immunol. 1993;91:268.

20. Chan A-W, Tetzlaff JM, Gøtzsche PC, Altman DG, Mann H, Berlin JA, et al. SPIRIT 2013 explanation and elaboration: guidance for protocols of clinical trials. BMJ. 2013;346:e7586.

21. Creswell JW. Research design : qualitative, quantitative, and mixed methods approaches. 4th ed. Thousand Oaks: SAGE Publications; 2014. 
22. Canadian Network for Respiratory Care. National Certified Respiratory Educator Learning Objectives. http://cnrchome.net. 2013. Accessed 20 Oct 2016.

23. Wallace $\mathrm{S}$, editor. A dictionary of education. 2nd ed. Oxford: Oxford University Press; 2015.

24. Falvo DR. Effective patient education: a guide to increased adherence. 4th ed. Sudbury: Jones \& Bartlett Publishers; 2011.

25. Stetson BA, Pichert JW, Roach RR, Lorenz RA, Boswell EJ, Schlundt DG. Registered dietitians' teaching and adherence promotion skills during routine patient education. Patient Educ Couns. 1992;19:273-80.

26. Lorenz RA. Teaching skills of health professionals. Diabetes Educ. 1989;15:149-52.

27. Meguro M, Barley EA, Spencer S, Jones PW. Development and validation of an improved, COPD-specific version of the St. George respiratory questionnaire. Chest. 2007;132:456-63.

28. Bourbeau J, Maltais F, Rouleau M, Guimont C. French-Canadian version of the chronic respiratory and St George's respiratory questionnaires: an assessment of their psychometric properties in patients with chronic obstructive pulmonary disease. Can Respir J. 2004;11:480-6.

29. Pinto LM, Gupta N, Tan W, Li PZ, Benedetti A, Jones PW, et al. Derivation of normative data for the COPD assessment test (CAT). Respir Res. 2014;15:68.

30. Jones PW. St. George's respiratory questionnaire: MCID. COPD. 2005;2:75-9.

31. Jones PW, Quirk FH, Baveystock CM, Littlejohns P. A self-complete measure of health status for chronic airflow limitation. The St. George's respiratory questionnaire. Am Rev Respir Dis. 1992;145:1321-7.

32. Kon SS, Canavan JL, Jones SE, Nolan CM, Clark AL, Dickson MJ, et al. Minimum clinically important difference for the COPD assessment test: a prospective analysis. Lancet Respir Med. 2014;2:195-203.

33. Jones PW, Harding G, Berry P, Wiklund I, Chen WH, Kline Leidy N. Development and first validation of the COPD assessment test. Eur Respir J. 2009;34:648-54.

34. Jones PW, Harding G, Wiklund I, Berry P, Tabberer M, Yu R, et al. Tests of the responsiveness of the COPD assessment test following acute exacerbation and pulmonary rehabilitation. Chest. 2012;142:134-40.

35. Osborne RH, Elsworth GR, Whitfield K. The health education impact questionnaire (heiQ): an outcomes and evaluation measure for patient education and self-management interventions for people with chronic conditions. Patient Educ Couns. 2007:66:192-201.

36. Belanger A, Hudon C, Fortin M, Amirall J, Bouhali T, Chouinard MC. Validation of a French-language version of the health education impact questionnaire (heiQ) among chronic disease patients seen in primary care: a cross-sectional study. Health Qual Life Outcomes. 2015;13:64.

37. Statistics Canada. Survey on Living with Chronic Condictions in Canada (SLCDC): Respiratory Component - 2011 Questionnaire. http://www23.statcan. gc.ca/imdb-bmdi/instrument/5160_Q6_V1-eng.pdf. 2011. Accessed August 30.

38. O'Donnell DE, Hernandez P, Kaplan A, Aaron S, Bourbeau J, Marciniuk D, et al. Canadian thoracic society recommendations for management of chronic obstructive pulmonary disease - 2008 update - highlights for primary care. Can Respir J. 2008;15(Suppl A):1a-8a.

39. Santé Québec. Et votre coeur, ça va ? Rapport de l'Enquête québécoise sur la santé cardiovasculaire 1990. In: Daveluy C, Chénard L, Levasseur M, Émond A editors. . Montréal: ministère de la Santé et des Services sociaux; 1994.

40. Moullec G, Favreau H, Lavoie KL, Labrecque M. Does a self-management education program have the same impact on emotional and functional dimensions of HRQoL? COPD. 2012:9:36-45.

41. Dahmen G, Rochon J, Konig IR, Ziegler A. Sample size calculations for controlled clinical trials using generalized estimating equations (GEE). Methods Inf Med. 2004:43:451-6.

42. Agusti A, Soler-Cataluna JJ, Molina J, Morejon E, Garcia-Losa M, Roset $M$, et al. Does the COPD assessment test (CAT(TM)) questionnaire produce similar results when self- or interviewer administered? Qual Life Res. 2015;24:2345-54.

43. Anie KA, Jones PW, Hilton SR, Anderson HR. A computer-assisted telephone interview technique for assessment of asthma morbidity and drug use in adult asthma. J Clin Epidemiol. 1996:49:653-6.

44. Shrout PE, Fleiss JL. Intraclass correlations: uses in assessing rater reliability. Psychol Bull. 1979;86:420-8.

45. Mokkink LB, Terwee CB, Patrick DL, Alonso J, Stratford PW, Knol DL, et al. The COSMIN study reached international consensus on taxonomy, terminology, and definitions of measurement properties for health-related patient-reported outcomes. J Clin Epidemiol. 2010;63:737-45.

46. Gupta SK. Intention-to-treat concept: a review. Perspect Clin Res. 2011:2:109-12.
47. Vittinghoff E, Glidden DV, Shiboski SC, McCulloch CE, Regression L. Regression methods in biostatistics: linear, logistic, survival, and repeated measures models. New York: Springer; 2012. p. 69-131.

48. Fitzmaurice GM, Laird NM, Ware JH. Applied longitudinal analysis. 2nd ed. Hoboken: Wiley; 2011.

49. Elobeid MA, Padilla MA, McVie T, Thomas O, Brock DW, Musser B, et al. Missing data in randomized clinical trials for weight loss: scope of the problem, state of the field, and performance of statistical methods. PLoS One. 2009;4:e6624.

50. Rothman KJ, Greenland S, Lash TL. Modern epidemiology. 3rd ed Philadelphia: Lippincott Williams \& Wilkins; 2008.

51. Osborne J. Improving your data transformations: applying the box-cox transformation. Pract Assessment Res Eval. 2010;15. Available online: http:// pareonline.net/getvn.asp? $=15 \& n=12$

52. Graneheim UH, Lundman B. Qualitative content analysis in nursing research: concepts, procedures and measures to achieve trustworthiness. Nurse Educ Today. 2004;24:105-12.

53. Lange P, Andersen KK, Munch E, Sorensen TB, Dollerup J, Kasso K, et al. Quality of COPD care in hospital outpatient clinics in Denmark: the KOLIBRI study. Respir Med. 2009;103:1657-62.

54. Adams SG, Pitts J, Wynne J, Yawn BP, Diamond EJ, Lee S, et al. Effect of a primary care continuing education program on clinical practice of chronic obstructive pulmonary disease: translating theory into practice. Mayo Clin Proc. 2012;87:862-70.

55. Hardy S, Smart D, Scanlan M, Rogers S. Integrating psychological screening into reviews of patients with COPD. Br J Nurs. 2014;23:832-6.

56. Kruijver IPM, Kerkstra A, Francke AL, Bensing JM, van de Wiel HBM. Evaluation of communication training programs in nursing care: a review of the literature. Patient Educ Couns. 2000;39:129-45.

57. Chan AW, Tetzlaff JM, Altman DG, Laupacis A, Gotzsche PC, Krleza-Jeric K, et al. SPIRIT 2013 statement: defining standard protocol items for clinical trials. Ann Intern Med. 2013;158:200-7.

58. Pintrich PR, Smith DAF, Garcia T, Mckeachie WJ. Reliability and predictive validity of the motivated strategies for learning questionnaire (MSLQ). Educ Psychol Meas. 1993:53:801-13.

59. Jones P, Miravitlles M, van der Molen T, Kulich K. Beyond FEV(1) in COPD: a review of patient-reported outcomes and their measurement. Int J Chron Obstruct Pulmon Dis. 2012;7:697-709.

60. Burgel PR, Escamilla R, Perez T, Carre P, Caillaud D, Chanez P, et al. Impact of comorbidities on COPD-specific health-related quality of life. Respir Med. 2013;107:233-41.

61. Durr S, Zogg S, Miedinger D, Steveling EH, Maier S, Leuppi JD. Daily physical activity, functional capacity and quality of life in patients with COPD. Copd. 2014;11:689-96.

62. de Torres JP, Casanova C, Hernandez C, Abreu J, Montejo de Garcini A, Aguirre-Jaime A, et al. Gender associated differences in determinants of quality of life in patients with COPD: a case series study. Health Qual Life Outcomes. 2006:4:72.

63. Sedeno MF, Nault D, Hamd DH, Bourbeau J. A self-management education program including an action plan for acute COPD exacerbations. Copd. 2009;6:352-8.

64. Wilke S, Spruit MA, Wouters EF, Schols JM, Franssen FM, Janssen DJ. Determinants of 1-year changes in disease-specific health status in patients with advanced chronic obstructive pulmonary disease: a 1-year observational study. Int J Nurs Pract. 2015:21:239-48.

65. Roberge P, Dore I, Menear M, Chartrand E, Ciampi A, Duhoux A, et al. A psychometric evaluation of the French Canadian version of the hospital anxiety and depression scale in a large primary care population. J Affect Disord. 2013:147:171-9. 